\section{The BDJ news page}

The BDJ accepts all general news items that might interest our readers. Press releases or articles should not exceed $\mathbf{5 0 0}$ words and may be edited. Please include a colour photograph if possible. As space for photographs is limited, priority will be to given to good quality and/or interesting pictures. Please send BDJ news items to Kate Craig.

\section{BES Prizes}

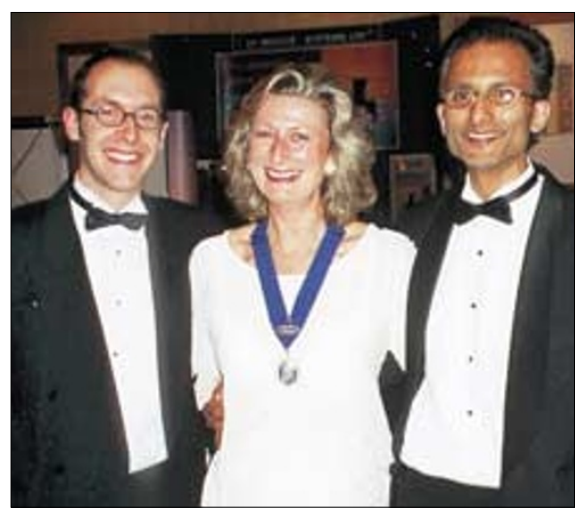

Above (l to $r$ ): Daniel Zillwood, Catherine Thomas and Santinder Matharu

At the recent British Endodontic Society Regional meeting in Chester, the President, Catherine Thomas, presented Daniel Zillwood and Santinder Matharu with the Vocational Dental Practitioners Prize and the BES/QED Poster Research prize respectively. The Society's next meeting will be the Spring Scientific Meeting and will be held at the Royal College of Physicians on Saturday 10th March 2001. Details from the BES Administrator, Mrs. A. Thomas, PO Box 707, Gerrards Cross, Bucks SL9 0XS

\section{BDA Representative Body}

There is a vacancy on the BDA Representative Body for a member from the East of Scotland branch. The place is available following the departure of a member for a new branch. A replacement is needed up to December 2002.

The Representative Body sets the policy and direction for the BDA and chooses the Executive Board. It meets a couple of times each year.

Any full member of the East of Scotland branch is eligible to stand for the position. In order to stand nominations must be signed by the nominee and three other

\title{
Dentistry on the wing
}

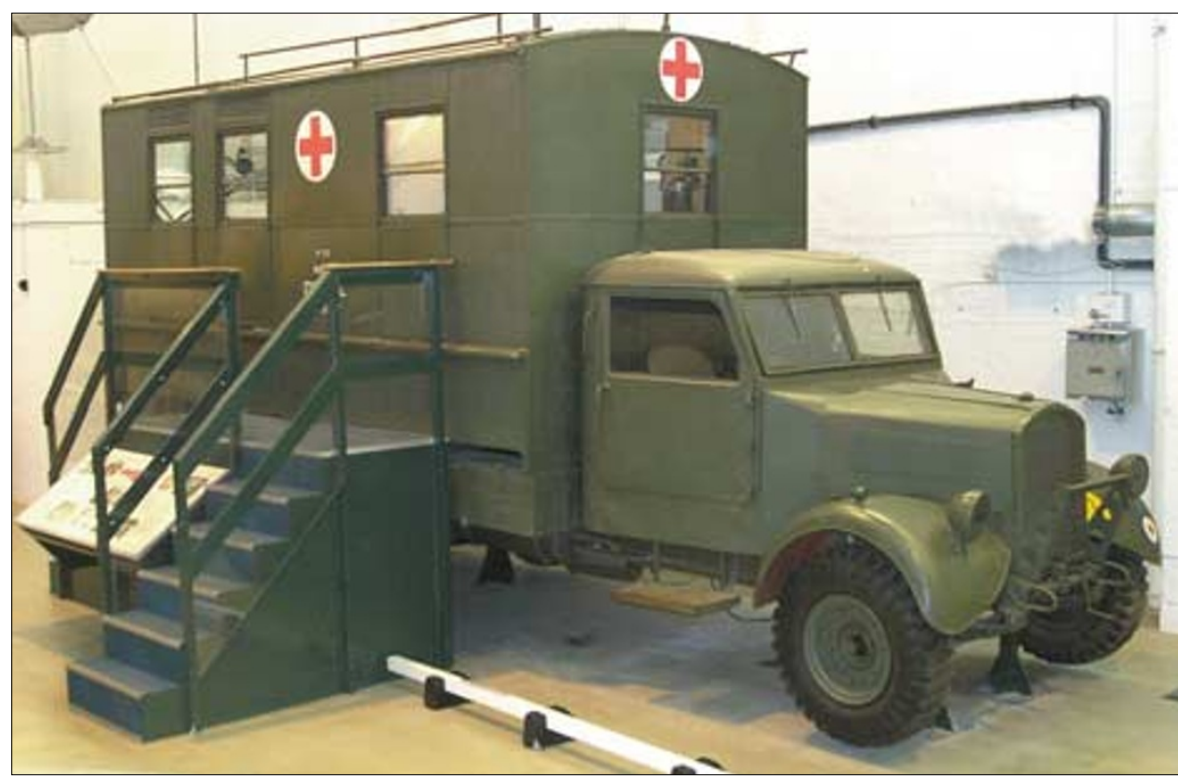

The Royal Air Force Museum at Cosford, near Telford, is in the process of carrying out an inventory of its collections. As part of this, they are cataloguing the contents of an RAF Dental Wagon, circa 1950s (above). The wagon contains several hundred assorted dental tools and pieces of equipment, some dating back to the 1930's. They are looking for a retired dentist, or dental assistant, who might be able to volunteer some time to work with the Curators at the Museum, helping to put names to all the tools. The work would have to be carried out during the working week, but could be spread out over a period of time. Unfortunately there is no financial support for this work, but there would be ample opportunity to see behind the scenes at the Museum. Anyone who thinks they could help should contact Al McLean or Clare Davies at Cosford, on 01902376200

members of the Branch. If you want a nomination form or would like further details please contact James Dawson, Chief Executive's Office, BDA, 64 Wimpole Street, London W1G 8YS (telephone 020 75634188 or e-mail: j.dawson@bdadentistry.org.uk). Nominations must be received by Thursday 12 April 2001.

If more than one nomination is received there will be a postal ballot. Nominees may submit an election address of up to 200 words.

\section{The BDA and the Dentists Act}

In view of the introduction, in the 1989 Health Act, of an Order-making power by the government that made it easier to make changes to the Dentists Act, a number of changes have been recognised by the BDA as essential to strengthen self regulation. Regular recertification is necessary so that dentists can demonstrate their competence and keep skills contemporary, as is the introduction of a performance review to allow the GDC to help rehabilitate dentists whose performance in certain areas is deficient. Mandatory vocational training should be introduced so that all new dental undergraduates undergo a year of supervised practice prior to being able to work independently. The GDC should also be able to impose conditions on registration, for example, so that a dentist may only practise under controlled conditions, and strengthened powers should be introduced to allow immediate suspension in certain circumstances. Regulation of professionals complementary to dentistry should be introduced and a formal complaints procedure to deal with private dental care should also be introduced.

The constitution of the GDC is to be revised in line as reported in BDJ 190:46.

\section{University dental teachers and research workers group}

Notice is hereby given that a meeing of the UDT\&RW Group will be held at British Dental Association headquarters, 64 Wimpole Street, London W1G 8YS on Thursday 26th April 2001 at 12.30pm to confirm tha accounts for the year 1999-00. If you wish to attend please contact: Joanna Woodcock

British Dental Association 64 Wimpole Streeet

London

W1G 8YS 